\title{
Diurnal Effect of Selenium Supplementation on Adult Female Wistar Rats made Hypothyroid by Methimazole
}

\author{
*MJ Adeniyi and FO Agoreyo \\ Department of Physiology, University of Benin, Benin-city, Nigeria
}

Received: June 30, 2017; Published: July 07, 2017

*Corresponding author: MJ Adeniyi, Department of Physiology, University of Benin, Benin-city, Nigeria, Tel: +2348066796517 ;

Email: 7jimade@gmail.com

\begin{abstract}
Diurnal variation in gastric emptying is known to affect the bioavailability of ingest. The present study sought to understand the effect of consumption of selenium in daytime or nighttime on some clinical features of hypothyroidism in female wistar rats. 36 adult female wistar rats weighing 120-150g were randomly divided into 6 groups: vehicle-treated, methimazole, daytime - selenium, nighttime-selenium, methimazole+ daytime-selenium and methimazole+ nighttime selenium groups. Hypothyroidism was induced through oral administration of $1.35 \mathrm{mg} / \mathrm{kg}$ body weight of methimazole. $7 \mathrm{mg} / \mathrm{ml}$ of Selenomethionine was administered through drinking water for two weeks. When compared with vehicletreated group, methimazole administration caused a significant $(\mathrm{P}<0.05)$ decrease in caudal cold tolerance (CCT) and Body Temperature (BT). Rats administered selenium during day-time showed a significantly higher $(\mathrm{P}<0.05)$ plasma glucose and decreased CCT. Nighttime selenium administration to hypothyroid rats resulted in a significant decrease $(\mathrm{P}<0.05)$ in plasma glucose. There was an insignificant change in CCT and BT in hypothyroid rats administered selenium in day-time. In conclusion, the study showed that daytime selenium consumption may exert more positive influence on hypothyroidism than nighttime selenium consumption.
\end{abstract}

Keywords: Methimazole; Hypothyroidism; Caudal cold tolerance; Body temperature; Selenium

Abbreviations: CCT: Caudal Cold Tolerance; BT: Body Temperature; NIH: National Institute of Health; VEH: Vehicle-Treated group; DTSE: DayTime Selenium group; NTSE: Night-Time selenium group

\section{Introduction}

Selenium is one of elements of the period table. It was discovered by Jons Jacob Belzelius in 1817. It is an essential trace element obtained majorly from foods and water. It functions as a cofactor for enzymes including antioxidant enzymes most especially, glutathione peroxidase and thyroxine-metabolizing enzyme such as 5-iodothyronine deiodinase, catalyzing the conversion of thyroxine to triiodothyronine [1]. Studies have established the link between selenium deficiency and thyroid dysfunctions. For instance, Berry and Larsen [2] and Kohrle [3] reported that selenium depletion in rats resulted in decrease in triodothyronine and increases in tetraiodothyronine and reverse triiodothyronine. Depletion of selenium caused reduction in expression of type I. Selenodeiodinase, a thyroid hormone metabolizing enzyme [4]. Healthy men placed on low selenium diet exhibited high plasma triiodothyronine [5]. In Northern Zaire, selenium supplementation decreased serum tetraiodothyronine, free thyroxine index and reverse triiodothyronine [6]. Works have demonstrated that increased selenium supplementation led to a decrease in antithyroid peroxidase antibodies at three months [7] and a rise in thyrotropin in rat serum [8]. In lactating rats, hypothyroidism induced by methimazole produced hypertrophied thyroid gland and change in body weight [9]. Cerebrum and cerebellum impairments in rats were also reported in an animal model of hypothyroidism induced by methimazole [9]. Other frequently reported clinical manifestations of hypothyroidism include cold, intolerance to cold and changes in glucose metabolism. Investigators have highlighted the influences of selenium supplementation on thyroid functions in states of health and diseases but there is limited information on the diurnal effect of dietary selenium on experimentally-induced hypothyroid symptoms in female wistar rats. Therefore, this study sought to determine the diurnal effect of dietary selenium on methimazole induced hypothyroidism in female rats.

\section{Materials and Methods}

\section{Site of The Study}

The experiment was carried out at a research laboratory in conjunction with the Department of Physiology, University of Benin, Benin-city, Edo State.

\section{Animal Care and Management}

Thirty six adult female wistar rats weighing 120-150g were used for the research work. They were divided into six groups consisting of six animals each. These rats were kept in five different 
cages with a wire mesh covering .They were fed pelletized grower's mash adlibitum, provided water through drinking trough and kept under 12 hour light and 12 hour darkness at room temperature.

\section{Ethical Certification}

The study was conducted in line with the guidelines of National Institute of Health (NIH) for the use of laboratory rats.

\section{Experimental Procedure}

The rats were weighed and randomly grouped into;

Group A: received distilled water for two weeks and was designated as Vehicle-treated group (VEH).

Group B: received $1.35 \mathrm{mg} / \mathrm{kg}$ of methimazole (P.O.) for two weeks and was designated as hypothyroid group (HYPO).

Group C: received $7 \mathrm{mg} / \mathrm{ml}$ of selenium supplementation in drinking water for two weeks between $6.00 \mathrm{am}$ and $6.00 \mathrm{pm}$ and was designated as Day-Time selenium group (DTSE).

Group D: received $7 \mathrm{mg} / \mathrm{ml}$ of selenium supplementation in drinking water for two weeks between $6.00 \mathrm{pm}$ and $6.00 \mathrm{am}$ and was designated as Night-Time selenium group (NTSE).

Group E: received $7 \mathrm{mg} / \mathrm{ml}$ of selenium supplementation for two weeks between $6.00 \mathrm{am}$ and $6.00 \mathrm{pm}$ and $1.35 \mathrm{mg} / \mathrm{kg}$ of methimazole (P.O.) for two weeks and was designated as hypothyroid treated group (HYPO+DTSE).

Group F: received $7 \mathrm{mg} / \mathrm{ml}$ of selenium supplementation for two weeks between $6.00 \mathrm{pm}$ and $6.00 \mathrm{am}$ and $1.35 \mathrm{mg} / \mathrm{kg}$ of methimazole (P.O.) for two weeks and was designated as hypothyroid treated group (HYPO+NTSE).

\section{Methods}

\section{Reagents and Supplies}

Organic selenium manufactured by World (Tianjin) Nutrition and Health Food Co. Ltd. China was purchased. Carbimazole was obtained locally from a registered pharmacy. Mercury in glass thermometer, glucometer (Accu-chek, Roche, Mannheim, Germany), stop watch, dissecting set, needles, syringes and chemicals were obtained locally.

\section{Diet}

The rats will be fed grower's mash feed from Tops Feeds. Administrations will be through feeding troughs.

The organic selenium was dissolved in drinking water at $7 \mathrm{mg} /$ $\mathrm{ml}$ based on the minimum dosage of the supplement for human.

\section{Administrations}

A human therapeutical dose of $1.35 \mathrm{mg} / \mathrm{kg}$ of carbimazole, an antithyroid drug (P.O.) was administered once per day. $7 \mathrm{mg} / \mathrm{ml}$ of selenium supplement (P.O) was administered for two weeks.

\section{Measurement of Body Temperature}

Using mercury-in-glass thermometer, the average of three consecutive readings of rectal temperature was determined and recorded before and after the experiment.

\section{Determination of Cold Tolerance Test (Cct)}

Cold Tolerance Test was carried according to the method of Talan et al. [10] with modification. While the animals were partially restrained, their tails were allowed to make contact with iced block. The average time it takes each animal to lift tail after three consecutive trials was recorded.

\section{Determination of Blood Glucose}

A prick was made on the distal part of rats' tails following partial restraint. Little quantity of blood was introduced through the strip of the automated blood glucose measuring device and the concentration of glucose was displayed by the glucometer.

\section{Statistical Analysis}

All data are expressed as mean standard error of the mean (SEM) for 5 rats per group. Statistical group analyses were performed with SPSS 20.0 statistical software. Statistical significant differences were accepted at $\mathrm{p}<0.05$ using One-way Analysis of Variance (ANOVA). Boniferroni test was be used to identify the significance of pair wise comparison of mean values among the group.

\section{Results}

(Figures 1-3).
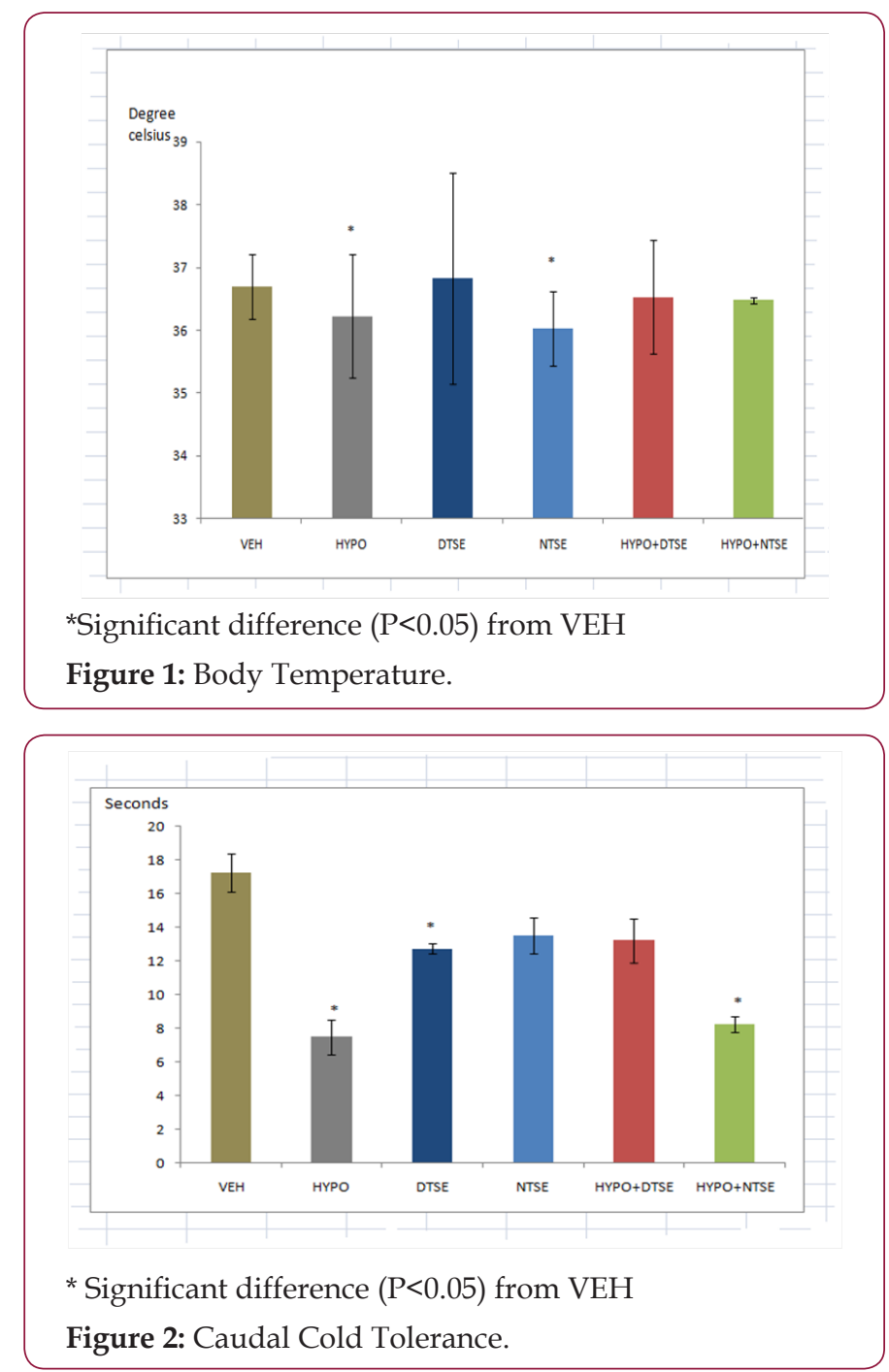


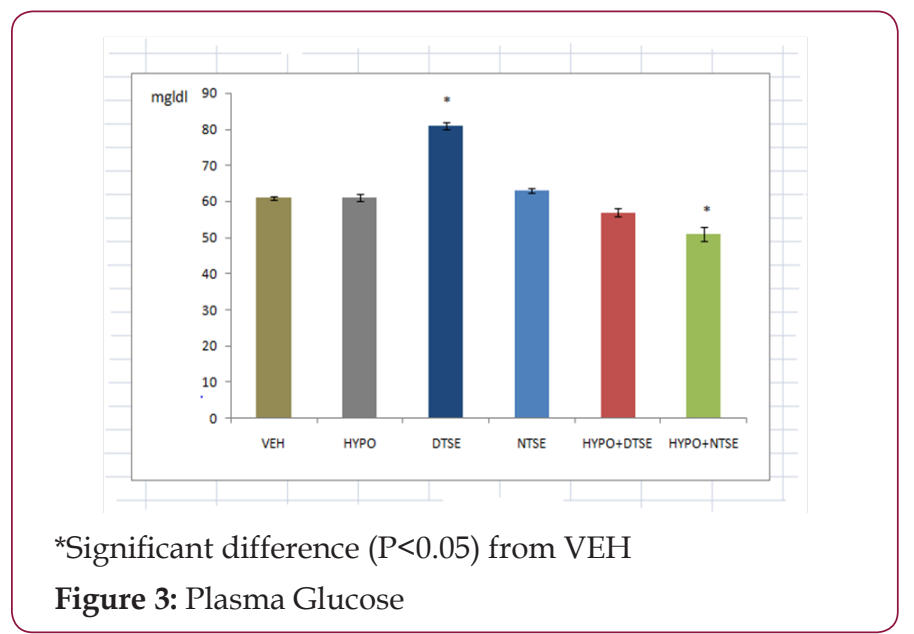

\section{Discussion and Conclusion}

While studies have shown that selenium deficiency impairs thyroid function [2-4], its supplementation improves cerebrum and cerebellum functions in rats [9]. The present study investigated the effect of diurnal consumption of the mineral on some frequently reported features of hypothyroidism. Female rats administered methimazole in this study showed decreases in body temperature and cold tolerance test as previously reported by researchers. Decreased body temperature indicated low metabolic rate and decreased caudal cold tolerance test reflected increased cold sensitivity. Although hypoglycemia is not a gold standard index of hypothyroidism, the present study could not confirm that methimazole induced hypothyroidism causes a change in plasma glucose level. Since increase in plasma glucose means availability of glucose for neuronal activities, the increased plasma glucose in female wistar rats administered selenium in the day-time could have led to the reduction in caudal cold tolerance test or increased cold sensitivity. Despite Mohammed et al. [11] reported that high selenium supplementation induced hypoglycemic effect that is comparable with glibenclamide, in this study the significance of reduction in cold tolerance time in rats given selenium supplementation in day time remains an enigma. In our study, night-time selenium consumption resulted in a significant decrease in body temperature. Despite the fact that low temperature prevents denaturation of proteins and in male play important role in spermatogenesis, the physiological relevance of the low temperature is unclear. Amara et al. [9] claimed that sodium selenite consumption by hypothyroid lactating rats had a beneficial effect. In our study, we observed that administration of organic selenium in the day-time to hypothyroid female wistar rats resulted to an insignificant change in body temperature, caudal cold tolerance and plasma glucose. Hence, we conclude that daytime selenium consumption may exert more positive influence on hypothyroidism than nighttime selenium consumption.

\section{References}

1. Golstein J, Corvilain B, Lamy F, Paquer D, Dumont JE (1988) 'Effect of selenium deficient diet on thyroid function of normal and perchlorate treated rats.' Acta Endocrinol 118(4): 495-502.

2. Berry MJ, Larsen PR (1994) The Role of Selenium in Thyroid Hormone Action 1994 Endocrine Society Bethesda.

3. Kohrle J (1994) Thyroid hormone deiodination in target tissues-a regulatory role for the trace Element selenium? Exp Clin Endocrinol 102(2): 63-89.

4. Beckett GJ, Hutchinson AR, Nicol F, Arthur JR (1988) A role for selenium in the hepatic 5' deiodination of thyroxine. J Endocrinol 117:287.

5. Hawkes Wayne Chris, Nancy L Keim (2003) 'Dietary Selenium Intake Modulates Thyroid Hormone and Energy Metabolism in Men.' J Nutr 133(11): 3443-3448.

6. Contempre B1, Duale NL, Dumont JE, Ngo B, Diplock AT (1992) 'Effect of selenium supplementation on thyroid hormone metabolism in an iodine and selenium deficient population.' Vanderpas J Clin Endocrinol (Oxf) 36(6): 579-583.

7. Sunde RA (2006) 'Selenium. In: Bowman B, Russell R, eds. Present Knowledge in Nutrition. $9^{\text {th }}$ (ed) Washington, DC: International Life Sciences Institute pp: 480-497.

8. Gladyshev VN, Jeang KT, Stadtman TC (1996) Selenocysteine, identified as the penultimate Cterminal residue in human T-cell thioredoxin reductase, corresponds to TGA in the human placental gene. Proc Natl Acad Sci 93(12): 6146-6151.

9. Amara IB Bouaziz H, Guermazi F, Zeghal N (2010) 'Effect of selenium on hypothyroidism induced by methimazole in lactating rats and their pups.' Acta boil Hung 61(2): 145-157.

10. Talan MI, Tatelman HM, Engel BT (1991) 'Cold tolerance and metabolic heat production in Male C57BL/6J mice at different times of day.' Physiol Behav 50(3): 613-616.

11. Ahmed Mohammed Kabir, Mohammed Aliyu, Tanko Yusuf, Musa Kabir Yusuf (2015)'Ameliorative Effect of Selenium Yeast on Blood Glucose Level in Streptozotocin induced Diabetes in Wistar Rats.' Cell Biology 3(1): 14-18.

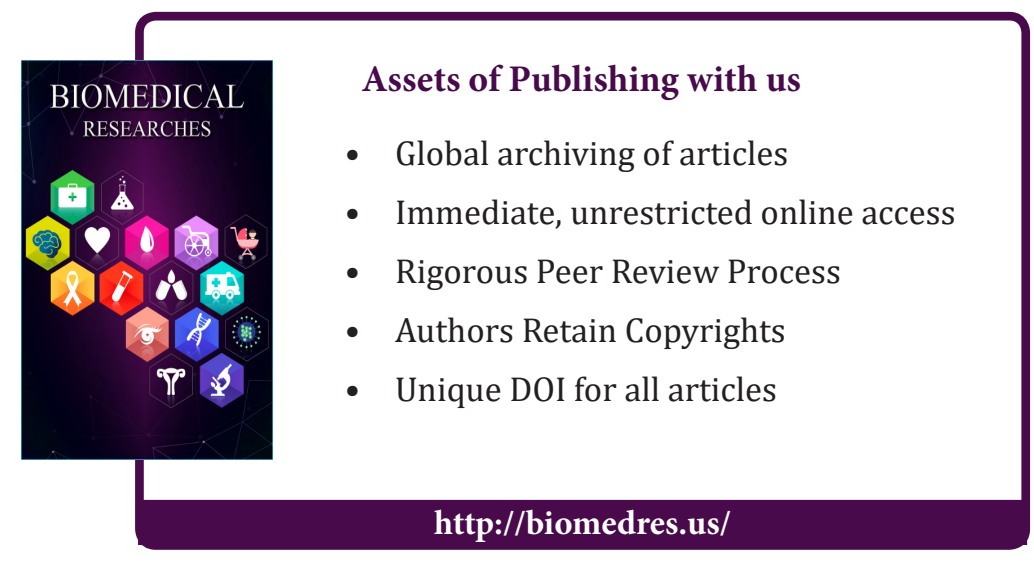

